The final publication is available at Elsevier via http://doi.org/10.1016/j.buildenv.2009.03.017 (C 2009. This manuscript

version is made available under the CC-BY-NC-ND 4.0 license http://creativecommons.org/licenses/by-nc-nd/4.0/

\title{
Numerical Analysis of Convective Heat Transfer in Fenestration with Between-the- Glass Louvered Shades
}

\author{
Mike Collins Syeda Tasnim John Wright \\ Department of Mechanical Engineering \\ University of Waterloo \\ Waterloo, Ontario, Canada
}

\begin{abstract}
A two-dimensional steady laminar natural convection model of a window cavity with between-panes louvers (i.e., slats) was developed by approximating the system as a vertical cavity with isothermal walls at different temperatures, and with rotateable baffles located midway between the walls. The baffles were set to a third temperature so that night-time and day-time conditions could be considered. The effects of wall spacing, baffle angle and temperature, and the wall-to-wall temperature difference were examined. It was found that the system is suited to a traditional one-dimensional analysis, and that the convective heat transfer is largely independent of the Rayleigh number for the conditions of practical interest.
\end{abstract}

\section{KEYWORDS}

Fenestration, Shading, Louvers, Heat Transfer, Between-Panes

\section{INTRODUCTION}

The objective of this paper is to numerically examine natural convection heat transfer in window cavities containing rotateable louvered shades. Such systems have become increasingly popular, and accurate heat transfer correlations are required for rating purposes and building 
energy analysis. Such systems have been examined extensively in recent times. To date, however, none have looked at the situation where the system is sunlit.

Rheault and Bilgen [1,2] examined the overall heat transfer rates of a window system using climatic conditions for a typical Canadian winter and summer. In their analytical work [1], the temperature variation across the louvers and over the thickness of each glazing was assumed to be minimal, and therefore conduction effects were ignored. Furthermore, the distance between the louver tips and the window glazing was relatively large. Therefore, it was assumed that the presence of the louvers did not interfere with the cavity flow when the louvers were at angles other than vertical. When the louvers were placed vertically, the problem was treated as two sideby-side cavities with the louvers as a dividing wall. Longwave radiation and convection transfer rates across the window system were considered. The numerical work concluded that the presence of louvers between the glazings could reduce heating and cooling loads. The analytical results were later verified by the results obtained in the experimental study [2].

Garnet [3] measured the centre glass heat transfer of a window system with an aluminium louvered blind between two panes of glass. Experiments were run at several different blind louver angles and three different pane spacings. It was observed that, for the blind in the fully open position, the presence of the blind decreased the window's thermal resistance. It was speculated that while in this position, conduction effects in the blinds was having a significant effect. For all cavity widths a steady improvement in the performance of the window was observed as the blind was closed.

Yahoda [4] and Yahoda and Wright [5,6] performed detailed modelling of the effective longwave radiative and solar/optical properties of a louvered blind layer that could be placed anywhere in the window system. The effective longwave radiative properties model was were based on fundamental radiant exchange analysis, and accounted for the louver width, spacing, angle of tilt, and emissivity. The effective solar-optical properties model treated solar beam and diffuse radiation separately. Finally, a simplified center-glass model of thermal transmissivity ( $U$ - 
factor) was proposed by combining the longwave radiation model with some simple convection correlations. This model was moderately successful.

Naylor and Collins [7] developed a two-dimensional numerical model of the conjugate convection, conduction and radiative heat transfer in a double glazed window with a betweenpanes louvered blind. They obtained numerical results both with and without the effects of thermal radiation. It was concluded that data from a conjugate convection-conduction CFD model can be subsequently combined with a very simple radiation model to estimate the $U$-factor of the complete window/blind enclosure.

Recently, Huang [8] conducted an experimental investigation similar to that of Garnet [3]. He examined the effects of louvers on the convective and radiative heat transfer inside a vertical window cavity using two sets of glazings; clear/clear and low-e/clear. His experiment used isothermal vertical surfaces at various pane spacings and louver angles to examine the centreglass $U$-factor. The results showed better window performance when the louvers were tilted from their fully open position and also when the low-e coating was used. More importantly, , it was discovered that correlations used to predict heat transfer in window cavities could be used to predict heat transfer in the present system [9]. To do so, the following assumptions were made:

- The system could be approximated as two vertical cavities of a width that is a function of louver tip to glass spacing

- There was no transfer of flow across the blind layer except at the ends of the cavity.

- That convective heat transfer was laminar natural convection correlations [10].

These assumptions were later verified via flow visualization performed by Almeida et al. [11]. Those studies further showed that turbulent transition was expected to begin at cavity widths exceeding $40 \mathrm{~mm}$.

A simplified convective heat transfer model was developed which was subsequently combined with Yahoda's [4] longwave radiation model to predict the centre-glass $U$-factor. The new model reproduced experimental data accurately. 
In this study, laminar natural convection heat transfer was studied numerically. A twodimensional model was used in keeping with established window analysis methodology. Convective heat transfer was considered for situations when the blind was at a third prescribed temperature relative to the glass temperatures. As a 3-temperaure analysis, simulation of heat transfer can be performed for cases where the shade is hotter than the glass; simulating absorbed solar radiation. That is, the system was analyzed for situations that represent sunlit conditions. In future work, the results produced here will be coupled with Yahoda's [4] longwave model, and comparisons will be made to the results of Huang [8].

Numerical results will be examined on two levels. First, the simulation results will provide information about flow structures and heat transfer that improve our understanding of the underlying heat transfer processes. Second, in keeping with a traditional one-dimensional centreglass analysis, particular attention will be paid to average convective heat transfer across the center portion of the cavity. The development of a correlation and comparison to the work of Huang [8] will be the subject of a future publication.

\section{PHYSICAL MODEL}

A tall vertical enclosure was chosen to represent the glazing cavity, and baffles located on the vertical centre line of the enclosure represented the blind louvers (Figure 1). The two window panes ( $\mathrm{AB}$ and $\mathrm{CD}$ ) were set apart at a distance, $W$, and a height, $H$, and were assumed to be isothermal. The end walls (BC and DA) were assumed to be adiabatic. The blind consisted of a set of evenly spaced isothermal baffles of width, $w$, and pitch, $P$, (pitch is the vertical distance between two consecutive louvers), which could be rotated about their centre to an angle, $\phi$, from

the horizontal. The baffles were assumed to be made of a material with high thermal conductivity, and flat with zero thickness.

Three temperatures were required to model the system. In this study, $T_{1}$ and $T_{2}$ are the left wall (AB) and right wall (CD) temperatures, and $T_{3}$ is the baffle temperature. For convenience, the 
temperature difference across the cavity and dimensionless baffle temperature are defined as $\Delta T=T_{2}-T_{1}$ and $\Theta_{3}=\left(T_{3}-T_{1}\right) /\left(T_{2}-T_{1}\right)$, respectively. Air properties were evaluated at a reference

temperature, $T_{\text {ref., }}$, that represents all three temperatures in the system with the baffle temperature predominating.

$$
T_{\text {ref }}=\frac{1}{2}\left(\frac{T_{1}+T_{2}}{2}+T_{3}\right)
$$

The air properties at $T_{\text {ref }}$ were taken from Hilsenrath [12].

The numerical model was an approximation of a real fenestration. For an actual window, there would be frame effects and only the center-glass region would be nearly isothermal. The idealized system was, however, consistent with the experimental setup used in the examination conducted by Huang [8]. Geometric parameters that remained constant for all numerical simulations are given in Table 1.

To understand the flow field and heat transfer characteristics of the system, three different wall spacings ( $W=17.8 \mathrm{~mm}, 25.4 \mathrm{~mm}$, and $40.0 \mathrm{~mm}$ ), three different wall-to-wall temperatures $\left(\Delta T=35^{\circ} \mathrm{C}, 10^{\circ} \mathrm{C}\right.$, and $-15^{\circ} \mathrm{C}$ ), three different baffle temperatures $\left(\Theta_{3}=0,0.5\right.$, and 1$)$, and three different baffle angles $\left(\phi=0^{\circ}, 45^{\circ}\right.$, and $-45^{\circ}$ ) were considered. Table 2 presents the matrix of conditions considered in this study.

\section{GOVERNING EQUATIONS}

Steady laminar natural convective heat transfer in the system is described by the fundamental conservation laws of mass, momentum, and energy. The Boussinesq approximation has been applied to the y-momentum equation, and the assumptions of an incompressible fluid flow with negligible viscous dissipation, and constant thermo-physical properties has been made.

The dimensional forms of the conservation equations are

$$
\frac{\partial u}{\partial x}+\frac{\partial v}{\partial y}=0
$$




$$
\begin{gathered}
\rho\left(u \frac{\partial u}{\partial x}+v \frac{\partial u}{\partial y}\right)=-\frac{\partial p}{\partial x}+\mu\left(\frac{\partial^{2} u}{\partial x^{2}}+\frac{\partial^{2} u}{\partial y^{2}}\right) \\
\rho\left(u \frac{\partial v}{\partial x}+v \frac{\partial v}{\partial y}\right)=-\frac{\partial p}{\partial y}+\mu\left(\frac{\partial^{2} v}{\partial x^{2}}+\frac{\partial^{2} v}{\partial y^{2}}\right)+g \rho \beta\left(T-T_{r e f}\right) \\
u \frac{\partial T}{\partial x}+v \frac{\partial T}{\partial y}=\alpha\left(\frac{\partial^{2} T}{\partial x^{2}}+\frac{\partial^{2} T}{\partial y^{2}}\right)
\end{gathered}
$$

Here, $u, v$, and $T$ are velocity components in the $x, y$ directions and temperature, respectively. $\rho$, $\mu$, and $\alpha$ are the density, dynamic viscosity and thermal diffusivity respectively. $\beta$ is the volume expansion coefficient where $\beta=1 / T_{\text {ref. }} g$ is gravitational acceleration, and $p$ is the pressure.

To solve Equations (2) to (5), the boundary conditions must be specified. No slip conditions were applied to all surfaces, the temperature was specified for both side walls and the baffles, and the end surfaces were adiabatic. The dimensional forms of the boundary conditions are:

$\mathrm{AB}$

CD

BC, DA

On the baffles

$$
\begin{aligned}
& u=v=0, T=T_{1} \\
& u=v=0, T=T_{2} \\
& u=v=0, \partial T / \partial y=0
\end{aligned}
$$$$
u=v=0, T=T_{3}
$$

The steady state governing equations were discretized by the finite-volume-method using a third order Quick scheme [13]. The solution procedures included the conjugate gradient method and the PISO algorithm (Pressure-Implicit with Splitting of Operations) [14] to ensure correct linkage between pressure and velocity. The typical number of iterations needed to obtain convergence was between 5,000 and 10,000. The tolerance of the normalized residuals upon convergence was set to $10^{-5}$ for every calculation case.

\section{MODEL CHECKS}


To provide confidence in the numerical model, steady laminar natural convection in a vertical cavity was also studied numerically, and compared to published solutions by Lee and Korpela [15], and Wright and Sullivan [16]. Comparisons were made by plotting the average Nusselt number, $N u_{a v}$, versus Rayleigh number, $R a$, at different aspect ratios, $\mathrm{A}=\mathrm{H} / \mathrm{W} . N u_{a v}$ as given by

$$
N u_{a v}=\frac{1}{H} \int_{0}^{H} N u_{\text {local }} d y
$$

where $N u_{\text {local }}$ is the local Nusselt number and is given by

$$
N u_{\text {local }}=\frac{h_{\text {local }} W}{k}
$$

Here, $k$ is the conductivity of the air, and $h_{\text {local }}$ is the local convective heat transfer coefficient and is defined by

$$
h_{\text {local }}=\frac{q^{\prime \prime}}{\Delta T}
$$

$q^{\prime \prime}$ is output by the software a $q^{\prime \prime}=-k \vartheta T / \vartheta x$ at the wall.

$R a$ is given by

$$
R a=\frac{\rho^{2} g \beta \Delta T W^{3}}{\mu^{2}} \operatorname{Pr}
$$

where $\operatorname{Pr}$ is the Prandtl number

$$
\operatorname{Pr}=\frac{\mu C_{p}}{k}
$$

Here, $C_{p}$ is the specific heat of the air. Fluid properties were evaluated at a reference temperature

$$
T_{\text {ref }}=\left(\frac{T_{1}+T_{2}}{2}\right)
$$

Results were determined for cavities with aspect ratios of $A=15,20$ and 40 using a uniform grid size of $(W \times H)$ of $60 \times 300$ (Figure 2). For the cases of $\mathrm{A}=15$ and 20, the predictions of Lee and Korpela [15] agree with the present numerical simulation to within $0.7 \%$, while the 
predictions of Wright and Sullivan [16] agree to within 1.5\%. At A=40, agreement is not as good, although $N u_{a v}$ is still predicted to within 0.1 .

In order to determine the proper grid size for this study, a grid dependency test was also conducted for the vertical cavity $(W=17.78 \mathrm{~mm})$ with the baffles in the horizontal position, and for the geometry presented in Table 1 and Figure 1 . Temperatures were set to $T_{1}=-10^{\circ} \mathrm{C}, T_{2}=25^{\circ} \mathrm{C}$, and $T_{3}=7.5^{\circ} \mathrm{C}$. These variables resulted in $R a=2.92 \times 10^{4}$. Seven different grid densities were used for the grid independence study. Considering both the accuracy and the computational time involved, a grid density $(W \mathrm{x} H)$ of $80 \times 434$ was chosen for $W=17.8 \mathrm{~mm}$. By the same method, grid densities of $120 \times 434$ and $200 \times 434$ were chosen for $W=25.4 \mathrm{~mm}$, and $40.0 \mathrm{~mm}$ spacings, respectively.

\section{ANALYSIS AND DISSCUSSION}

It is useful to first examine the flow structures and heat transfer to improve our understanding of the underlying heat transfer processes. Figures 3 to 5 show isothermal lines and velocity vectors at the top of selected cavities. Figure 3 shows the effect of baffle angle and temperature for $W=17.8 \mathrm{~mm}, T_{1}=15^{\circ} \mathrm{C}$, and $T_{2}=25^{\circ} \mathrm{C}$, Figure 4 shows the effect of cavity width and baffle temperature for $\phi=0 \mathrm{deg}, T_{1}=15^{\circ} \mathrm{C}$, and $T_{2}=25^{\circ} \mathrm{C}$, and Figure 5 shows the effects of cavity width and wall temperatures for $\phi=0 \mathrm{deg}, T_{1}=15^{\circ} \mathrm{C}$, and $T_{2}=25^{\circ} \mathrm{C}$ for $W=17.8 \mathrm{~mm}$ and $25.4 \mathrm{~mm}$.

The effect of baffle temperature is shown in Figures 3 and 4 . For $\Theta_{3}=0.5$, the system is geometrically and thermally symmetric. As such, the isotherms on both sides of the cavity are also symmetric (albeit in the opposite direction), indicating an equal amount of heat transfer at both surfaces. When $\Theta_{3}=0$, however, there is no temperature difference between the left wall and the baffles. As such, the isotherms are all between the right wall and the baffles. The opposite occurs when $\Theta_{3}=1$. Finally, while the vector plots show a turn-around region at the tops of the cavities, the isothermal lines do not penetrate appreciably to the opposite side of the cavity for 
any of the cases. It appears as if the turn-around region at the cavity ends is very short. This suggests that the end regions of the cavity have little effect on the heat transfer between the walls.

The effects of baffle angle are demonstrated by Figure 3. In all cases, the heat transfer at the baffle tips is increased due to increased fluid flow when the baffle tips are in close proximity to the walls. This effect was also seen in the results of Huang [8] and Garnet [3] who found that an open blind, when the louvers and glass were in close proximity, resulted in larger thermal transmission then a similar system with no blind present. Furthermore, it is noted that the isotherms extend into, but not beyond the baffle layer in all cases. The corresponding vector plots show that convective cells form between the baffles, and no significant transfer of fluid occurs between opposite sides of the cavity via the baffle layer. This phenomenon supports the treatment of the system as two vertical cavities (right wall-baffles and baffles-left wall).

The effects of cavity width are demonstrated by Figures 4 and 5. The fluid velocity increases as the spacing increases, resulting in larger turn-around regions near the cavity ends. In practice, fortunately, a $40.0 \mathrm{~mm}$ wide window cavity is extremely rare. The turn-around regions that represent the more realistic windows $(17.8 \mathrm{~mm}$ and $25.4 \mathrm{~mm})$ is still small. It is also noted that in general, the isothermal lines become denser at the walls as the cavity spacing decreases. Heat transfer is therefore highest for the lowest pane spacing.

The effects of wall temperature are shown in Figure 5. The fluid velocity increases only slightly with the increase of $\Delta T$ for both widths. Furthermore, the cells located between the louvers reverse direction depending on which wall is hotter. Overall however, the temperature difference has little impact on the flow structures.

To evaluate how the baffles affect the heat transfer, it is necessary to observe the variations of $\mathrm{Nu}_{\text {local }}$ on the walls. Due to the fact that this is a three temperature problem, negative and positive Nusselt numbers can result where the sign is not indicative of the direction of heat flow. For this discussion, positive $N u_{\text {avg }}$ indicates that heat flux is from the surface, while negative $N u_{\text {avg }}$ indicates that heat flux is into the surface. 
Figure 6 shows an example of $N u_{\text {local }}$ along the right wall of the cavity for $W=17.78 \mathrm{~mm}, \phi=0^{0}$, $T_{1}=15^{\circ} \mathrm{C}$, and $T_{2}=25^{\circ} \mathrm{C}$. As was predicted in the preceding paragraphs, one can observe that the proximity of the baffle tips producing a significant periodic effect on the $N u_{\text {local }}$ distribution, where the peak values of $\mathrm{Nu}_{\text {local }}$ indicate the positions of the louvers. The small turn-around region the top and bottom of the cavity are also confirmed. More importantly, the heat transfer is shown to be steady-periodic after the $1^{\text {st }}$ baffle from either end of the cavity. The baffles prevent boundary layer growth on the cavity walls. As the problem is symmetric, $N u_{\text {local }}$ at the left wall can be examined via the same plot where $\theta_{3, \text { left }}=\left|\theta_{3}-1\right|$ and the $N u_{\text {localleft }}=-N u_{\text {local }}$. For example, to examine $\mathrm{Nu}_{\text {local }}$ on the left wall for $\theta_{3}=1$, then look at the results for $\theta_{3}=0$, and take the negative value of the resulting $N u_{\text {local }}$.

The previous result is a fortunate occurrence in that most windows are analyzed from a onedimensional centre-glass perspective, and ultimately a center-glass $U$-factor would be required for use in window rating software and building energy studies. As such, a center-glass Nusselt number, $N u_{c g}$, has been calculated at the center of the cavity between two consecutive louvers

$$
N u_{c g}=\frac{1}{2 P} \int_{y_{s}}^{y_{e}} N u_{l o c a l} d y
$$

Figure 7 shows $N u_{c g}$ for all situations of $0^{\circ}, 45^{\circ}$, and $-45^{\circ}$, respectively, and on the right wall.

The symmetry of the heat transfer is further demonstrated in Figure 7 . As before, $N u_{c g}$ at the left wall can be examined via the same plot where $\theta_{3, l e f t}=\left|\theta_{3}-1\right|$ and the $N u_{c g, l e f t}=-N u_{c g}$. Therefore, when $\Theta_{3}=0.5$, and the baffle temperature is at the average of the two vertical walls temperatures, $N u_{c g}$ on the left wall equals the negative of that on the right wall. Furthermore, when $\Theta_{3}=1$, the louver and the right wall are at the same temperature, and when $\Theta_{3}=0$, the louver and the left wall are at the same temperature. Under these circumstances, there should be little heat transfer between the baffle and the wall. The figures show that this is indeed the case, and a value of $\mathrm{Nu}_{c g}$ near zero results. For the opposite situation of heat transfer between the baffle and 
the left wall when $\Theta_{3}=1$, and between the baffle and the right wall when $\Theta_{3}=0$, the maximum $N u_{c g}$ occurs. Practically, the symmetrical nature of the problem means that the same correlation would suffice for both sides of the system.

The effects of pane spacings and temperature difference on $N u_{c g}$ are also presented in these figures. $N u_{c g}$ is highest for the lowest wall spacing in all cases. Furthermore, in most cases, $N u_{c g}$ is almost independent of $R a$. The exceptions are the high $R a$ cases (i.e., when $W=40 \mathrm{~mm}$ ) and the high temperature cases $(\Delta T=35 \mathrm{~K})$ coupled with a small baffle tip to wall spacing (i.e. $\phi=0^{\circ}$ and $W=17.8 \mathrm{~mm}$ ), and a large baffle-wall temperature difference (i.e., $\theta_{3}=1$ at right wall or $\theta_{3}=0$ at the left wall). Considering the $40 \mathrm{~mm}$ spacing, the calculated $R a$ 's are large and heat transfer in those cavities may be dominated by advection. It is also likely that the assumption of steady laminar flow for the widest pane spacing is not valid. Practically, however, windows are rarely built with $40 \mathrm{~mm}$ spacings due to structural considerations. These cases were examined out of curiosity. Concerning the second exception, the proximity of the baffle to the wall likely enhanced the cellular flow between the baffles, and enhanced the heat transfer. However, the conditions required for this to occur are at the limits of the practical cases that would be considered in a building energy analysis, and the resulting change in $N u_{c g}$ was not significant. Practically, it may be possible to represent the heat transfer in the system in a way that decouples $R a$ and $N u_{c g}$. As was suggested by Huang [8], the baffle tip-wall spacing appears to be the main geometric parameter needed for a correlation.

\section{CONCLUSIONS}

A finite-volume model of a glazing cavity with between-panes louvers has been developed and validated. Examination of the numerical results suggested that a number of assumptions can be applied to the formulation of a simplified heat transfer model. These assumptions relate to the 
treatment of direct convection between the glass, the intra-louver heat transfer, and the glass-tolouver heat transfer characteristics.

- The energy transfer that would occur at the end regions, when the flow reverses cavity sides, and by air entrainment directly through the louvers, was found to be negligible. From the numerical model, $\mathrm{Nu}_{\text {local }}$ was influenced at the ends of the cavity over a small distance, and therefore, the turn-around region is also small. Flow across the cavity was also negligible due to the formation of cells between the louvers. For these reasons, the convective heat transfer could be represented as the convective heat transfer from the glass-to-blind and blind-to-glass, without including a glass-to-glass term.

- $\quad N u_{\text {local }}$ reached a steady-periodic state over a very short distance. Practically, this supports the one-dimensional centre-glass analysis preferred by building modelers.

- It was shown that the temperature drop across the cavity exists mostly between the blind tips and the glass. The convective cells that form between the slats create mixing which makes the blind-section of the cavity essentially isothermal (i.e., with negligible resistance to heat flow). Therefore, no resistance needs to be assigned to the blind section.

- The isotherms spread slightly into the spaces between the louvers. On the basis of this observation it seemed reasonable to treat convective heat transfer between the glass and the blind using established vertical cavity correlations, where the width of the cavity is based on the glass-to-blind spacing with some sort of geometric correction factor applied. That is $R a$ would be calculated on the basis of a cavity width which is a strong function of slat angle. Combining these conclusions, the convective heat transfer in a window cavity with a blind can be treated as a combination of two vertical cavities from the glass-to-blind and blind-to-glass without accounting for the blind section. The cavity width will be some modified width based on the slat geometry and the slat tip-to-glass spacing. 
A correlation can be produced from these results, however, such an exercise is outside the scope of this paper. A future paper will be dedicated to the development of a $N u_{c g}$ correlation, and the comparison of results to the work of Huang [8].

\section{ACKNOWLEDGEMENTS}

The Natural Sciences and Engineering Research Council of Canada and The CANMET

Energy Technology Centre are gratefully acknowledged for their support of this work.

NOMENCLATUREA Aspect Ratio, dim

\begin{tabular}{|c|c|}
\hline$C_{p}$ & Specific heat, J/kgK \\
\hline$g$ & Gravity, $\mathrm{m}^{2} / \mathrm{s}$ \\
\hline$h$ & Heat transfer coef., W/m² K \\
\hline$H$ & Cavity height, mm \\
\hline$k$ & Conductivity, W/mK \\
\hline $\mathrm{Nu}$ & Nusselt number, dim \\
\hline$p$ & Pressure, $\mathrm{Pa}$ \\
\hline$P$ & Louver pitch, mm \\
\hline $\operatorname{Pr}$ & Prandtl number, dim \\
\hline$q "$ & Heat flux, $\mathrm{W} / \mathrm{m}^{2}$ \\
\hline$R a$ & Rayleigh number, dim \\
\hline$T$ & Temperature, ${ }^{\circ} \mathrm{C}, \mathrm{K}$ \\
\hline$U$ & Thermal transmissivity, $\mathrm{W} / \mathrm{m}^{2} \mathrm{~K}$ \\
\hline$u, v$ & Velocity, m/s \\
\hline$w$ & Louver width, mm \\
\hline$W$ & Cavity width, mm \\
\hline$\alpha$ & Thermal diffusivity, $\mathrm{m}^{2} / \mathrm{s}$ \\
\hline
\end{tabular}




$\begin{array}{cc}\Delta & \text { change/difference } \\ \phi & \text { Louver angle, deg } \\ \rho & \text { Density, } \mathrm{kg} / \mathrm{m}^{3} \\ \mu & \text { Viscosity, } \mathrm{kg} / \mathrm{ms} \\ \Theta & \text { Temperature, dim }\end{array}$

\section{Subscripts}

$\begin{array}{ll}\text { av } & \text { Average } \\ c g & \text { Centre-Glass } \\ \text { left } & \text { Left Wall } \\ \text { local } & \text { Local } \\ r e f & \text { Reference } \\ 1 & \text { Left Wall/Left Glass } \\ 2 & \text { Right Wall/Right Glass } \\ 3 & \text { Louver/Baffle }\end{array}$

\section{REFERENCES}

[1] Rheault, S. and Bilgen, E., 1989, “Heat Transfer Analysis in an Automated Venetian Blind Window System”, Journal of Solar Energy Engineering, 111, pp. 89-95.

[2] Rheault, S. and Bilgen, E., 1990, “Experimental Study of Full-Size Automated Venetian Blind Windows”, Solar Energy, 44(3), pp. 157-160.

[3] Garnet, J. M., 1999, “Thermal performance of Windows with Inter-Pane Venetian Blinds”, Ma.Sc Thesis, University of Waterloo, Waterloo, Ontario, Canada. 
[4] Yahoda, S. D., 2002, “Methods of Estimating the Effective Longwave and Solar Optical Properties of a Venetian Blind Layer for Use in Centre-Glass Glazing Analysis,” Ma.Sc. Thesis, University of Waterloo, Waterloo, Ontario, Canada.

[5] Yahoda, S. D., and Wright, J. L., 2004, "Methods for Calculating the Effective Longwave and Solar Optical Properties of a Venetian Blind Layer”, ASHRAE Transactions, 110, part 1.

[6] Yahoda, S. D., and Wright, J. L., 2004, “Heat Transfer Analysis of a Between-Panes Venetian Blind Using Effective Longwave Radiative Properties”, ASHRAE Transactions, 110, part 1.

[7] Naylor, D., and Collins, M., 2004, “Evaluation of an Approximate Method for Predicting the U-Value a Window with a Between-Panes Louvered Shade”, Proceedings of CHT.

[8] Huang, N., 2005, “Thermal performance of double glazed windows with inter-pane Venetian blinds”, Ma.Sc. Thesis, University of Waterloo, Waterloo, Ontario, Canada.

[9] Wright, J.L., Collins, M.R., and Huang, N.Y.T, 2008, “Thermal Resistance of a Window with an Enclosed Venetian Blind: A Simplified Model”, ASHRAE Transactions, 114(1), pp. 1-12.

[10] Wright, J.L., 1996, “ A Correlation to Quantify Covective Heat Transfer Between Vertical Window Glazings”, ASHRAE Transactions, 102(1), pp 940-946,

[11] Almeida, F., Naylor, D., and Oosthuizen, P.H., 2008, “An Interferometric Study of Free Convection in a Window With a Heated Between-Panes Blind”, $3^{\text {rd }}$ Canadian Solar Buildings Conference, Fredericton, NB, Canada, Aug 20-22.

[12] Hilsenrath, T., 1955, "Thermal Properties of Gases", National Bureau of Standards Circular 564.

[13] Versteeg, H. K., Malalasekera, W., 1995, "An introduction to Computational Fluid Dynamics" Prentice Hall, Pearson Education Limited, England. 
[14] Ferziger, J., and Peric, M., 1996 "Computational Methods for Fluids Dynamics $1^{\text {st }}$ edition", Springer and Verlag, Berlin Hedelberg.

[15] Lee, Y., and Korpela, S.A., 1983, "Multicellular natural convection in a vertical slot”, J. Fluid Mech., 126, pp. $91-121$.

[16] Wright, J.L., and Sullivan, H.F., 1994, “A two-dimensional numerical model for natural convection in a vertical rectangular window cavity”, ASHRAE Transactions, 100(2), pp. 11931206. 
Table 1: Constant geometric parameters used in the numerical model

\begin{tabular}{|l|l|l|l|}
\hline $\boldsymbol{H}(\mathbf{m m})$ & $\boldsymbol{w} \mathbf{( m m )}$ & No. of baffles & Pitch $\boldsymbol{P}(\mathbf{m m})$ \\
\hline 367.0 & 14.8 & 30 & 11.8 \\
\hline
\end{tabular}


Table 2: Input variables used in the numerical model

\begin{tabular}{|c|c|c|c|c|c|c|}
\hline$T_{1}\left({ }^{\circ} \mathrm{C}\right)$ & $T_{2}\left({ }^{\circ} \mathrm{C}\right)$ & $\boldsymbol{\Theta}_{3}$ & $T_{3}\left({ }^{\circ} \mathrm{C}\right)$ & $\Delta T\left({ }^{\circ} \mathrm{C}\right)$ & $W(\mathbf{m m})$ & $\phi$ (deg.) \\
\hline-10.0 & 25.0 & 0.0 & -10.0 & 35.0 & \multirow{9}{*}{$17.8 / 25.4 / 40.0$} & \multirow{9}{*}{$-45,0,45$} \\
\hline-10.0 & 25.0 & 0.5 & 7.5 & 35.0 & & \\
\hline-10.0 & 25.0 & 1.0 & 25.0 & 35.0 & & \\
\hline 15.0 & 25.0 & 0.0 & 15.0 & 10.0 & & \\
\hline 15.0 & 25.0 & 0.5 & 20.0 & 10.0 & & \\
\hline 15.0 & 25.0 & 1.0 & 25.0 & 10.0 & & \\
\hline 40.0 & 25.0 & 0.0 & 40.0 & -15.0 & & \\
\hline 40.0 & 25.0 & 0.5 & 32.5 & -15.0 & & \\
\hline 40.0 & 25.0 & 1.0 & 25.0 & -15.0 & & \\
\hline
\end{tabular}



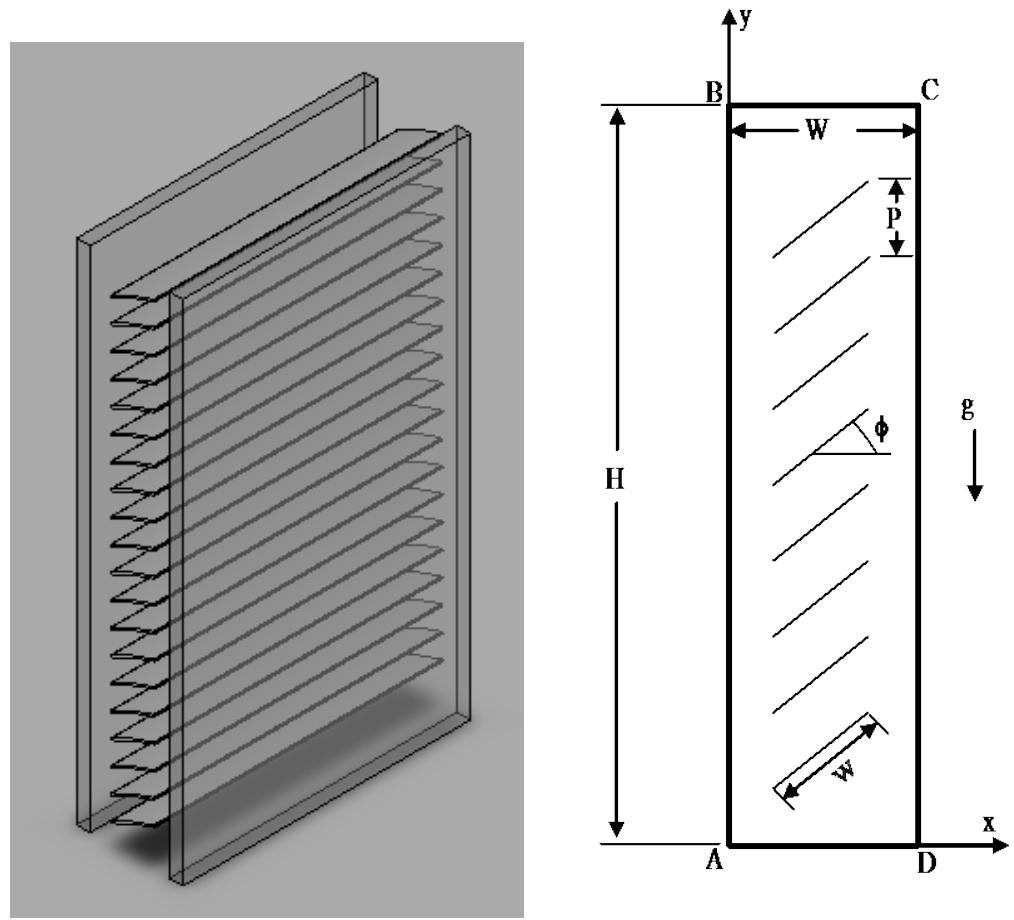

Figure 1: (a) Blind louvers enclosed between glass panes and (b) computational domain. 


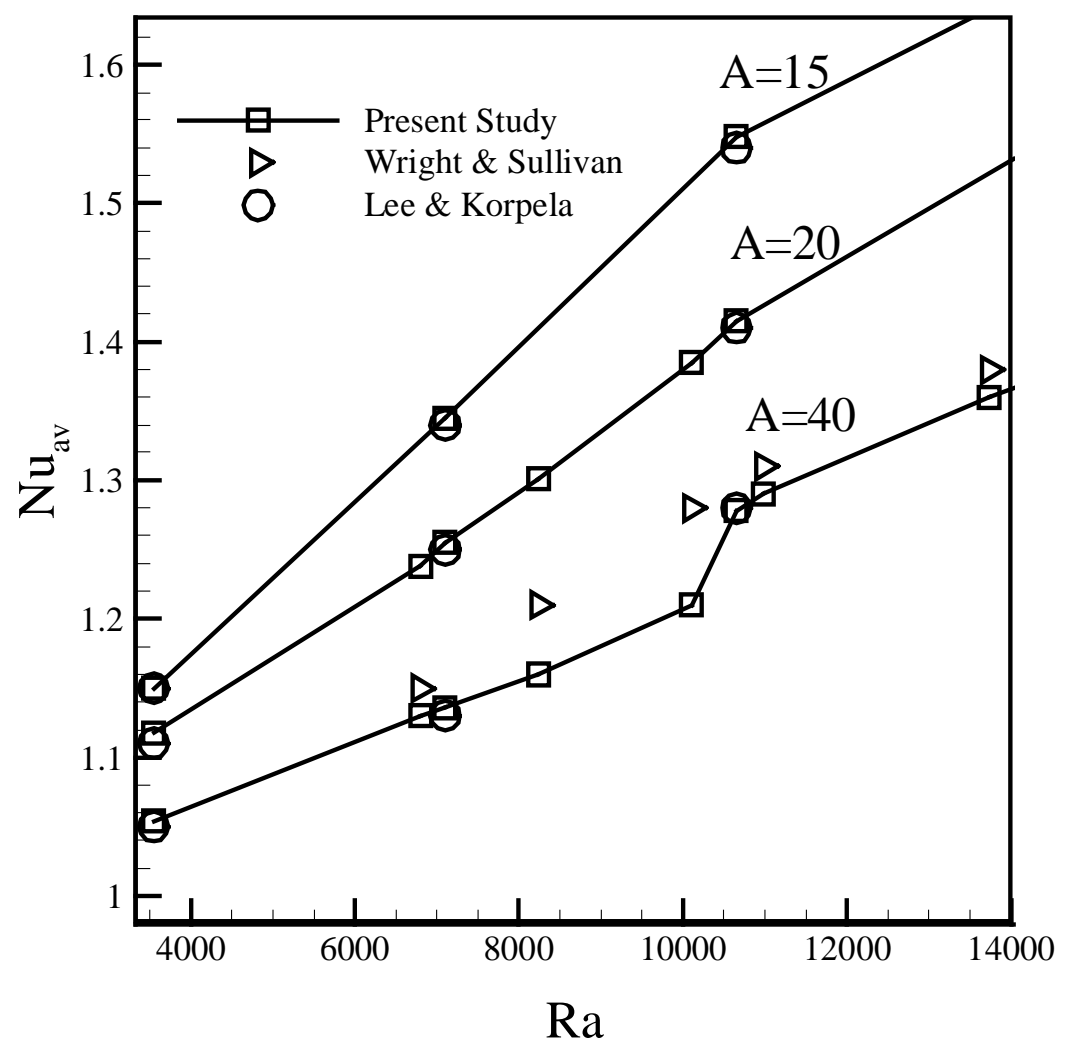

Figure 2: Comparison of the $N u_{a v}$ for the hot wall of the cavity versus Lee and Korpela [12] and Wright and Sullivan [13] 

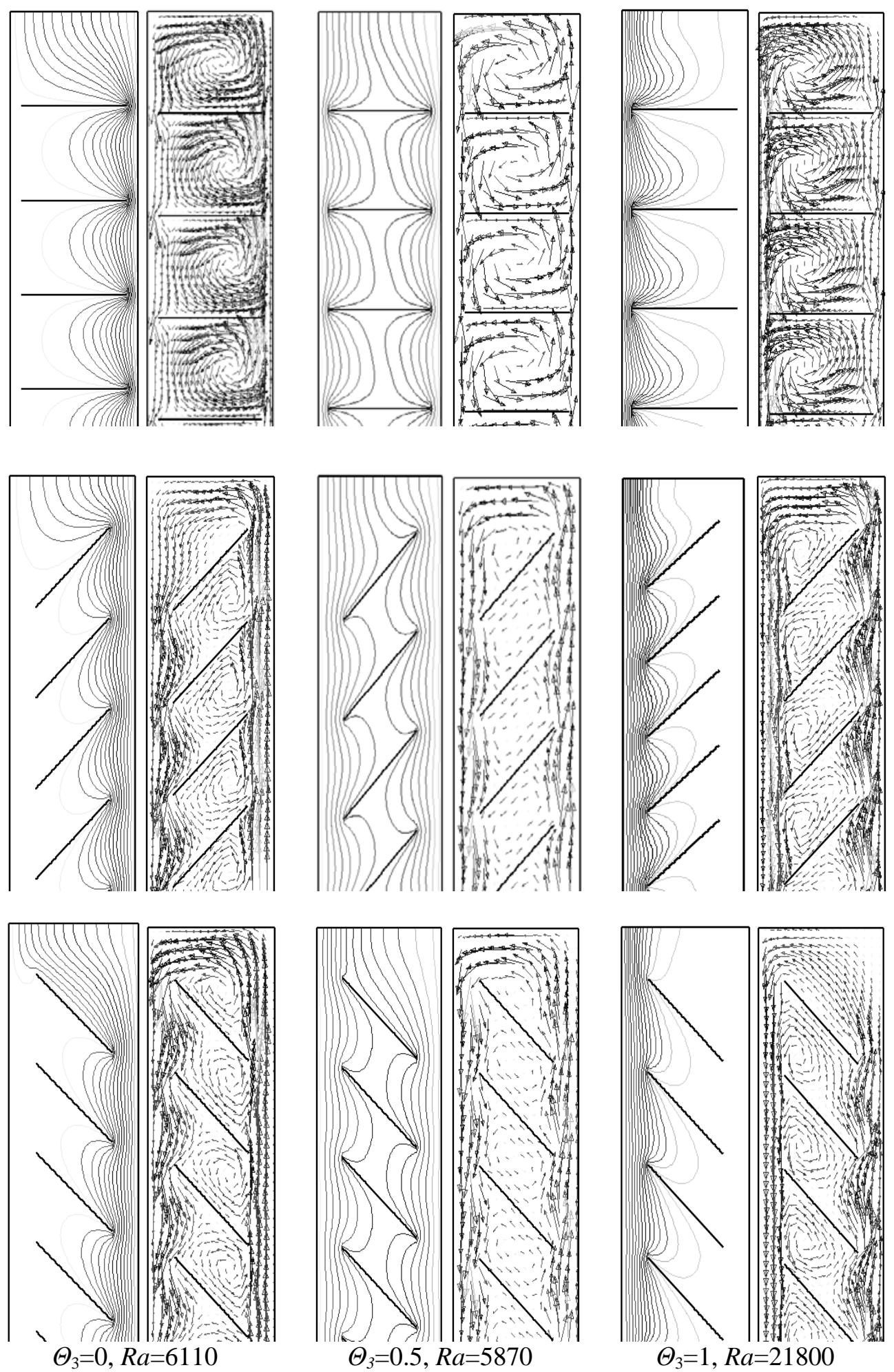

Figure 3: Isothermal lines and velocity vectors for $\phi=0{ }^{\circ}$ (top), $45^{\circ}$ (mid), and $-45^{\circ}$ (bot). $W=17.8 \mathrm{~mm}, T_{1}=15^{\circ} \mathrm{C}$ and $T_{2}=25^{\circ} \mathrm{C}$. 

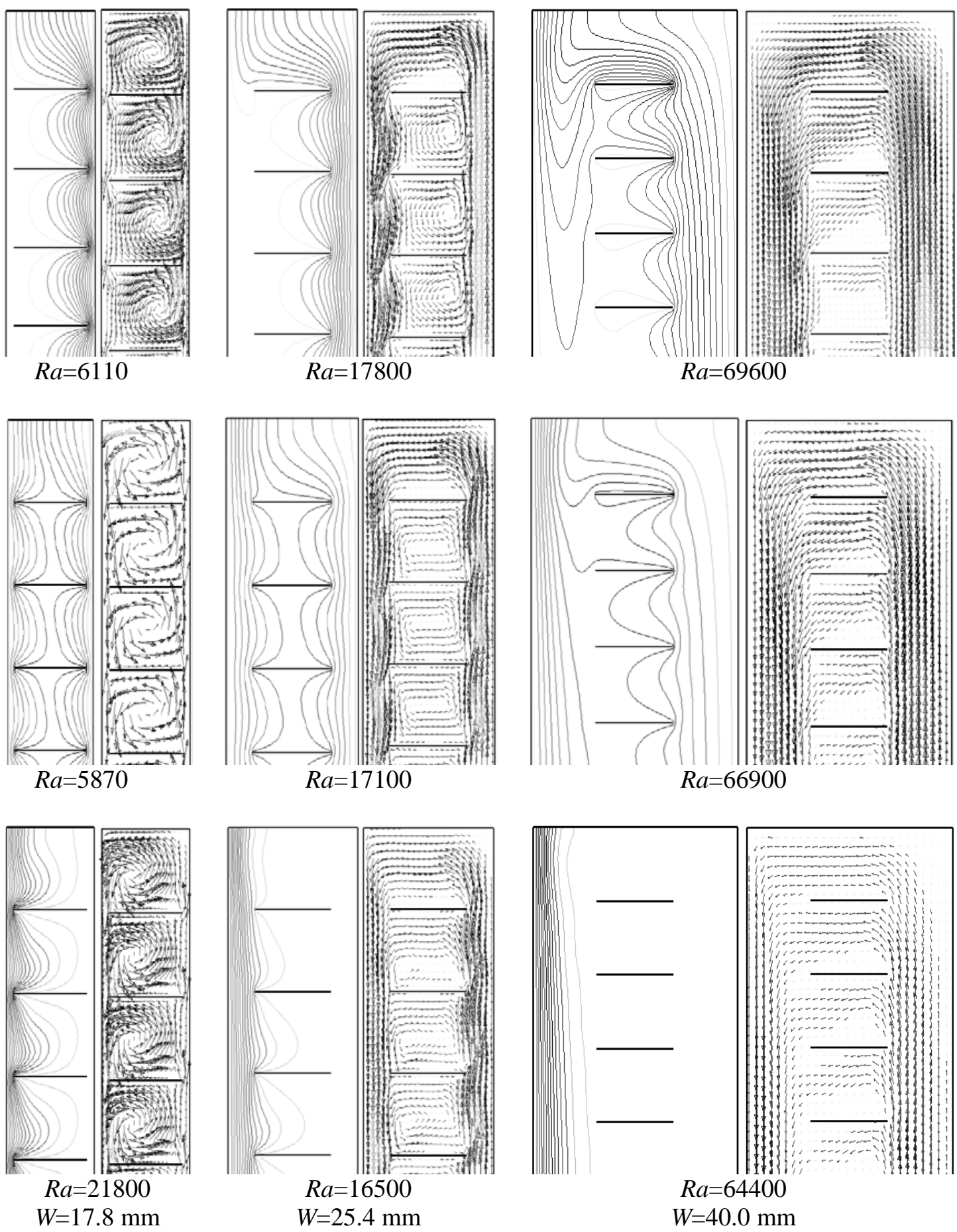

Figure 4: Isothermal lines and velocity vectors for $\Theta_{3}=0$ (top), 0.5 (mid), and 1 (top). $\phi=0^{0}$, $T_{1}=15^{\circ} \mathrm{C}$, and $T_{2}=25^{\circ} \mathrm{C}$. 

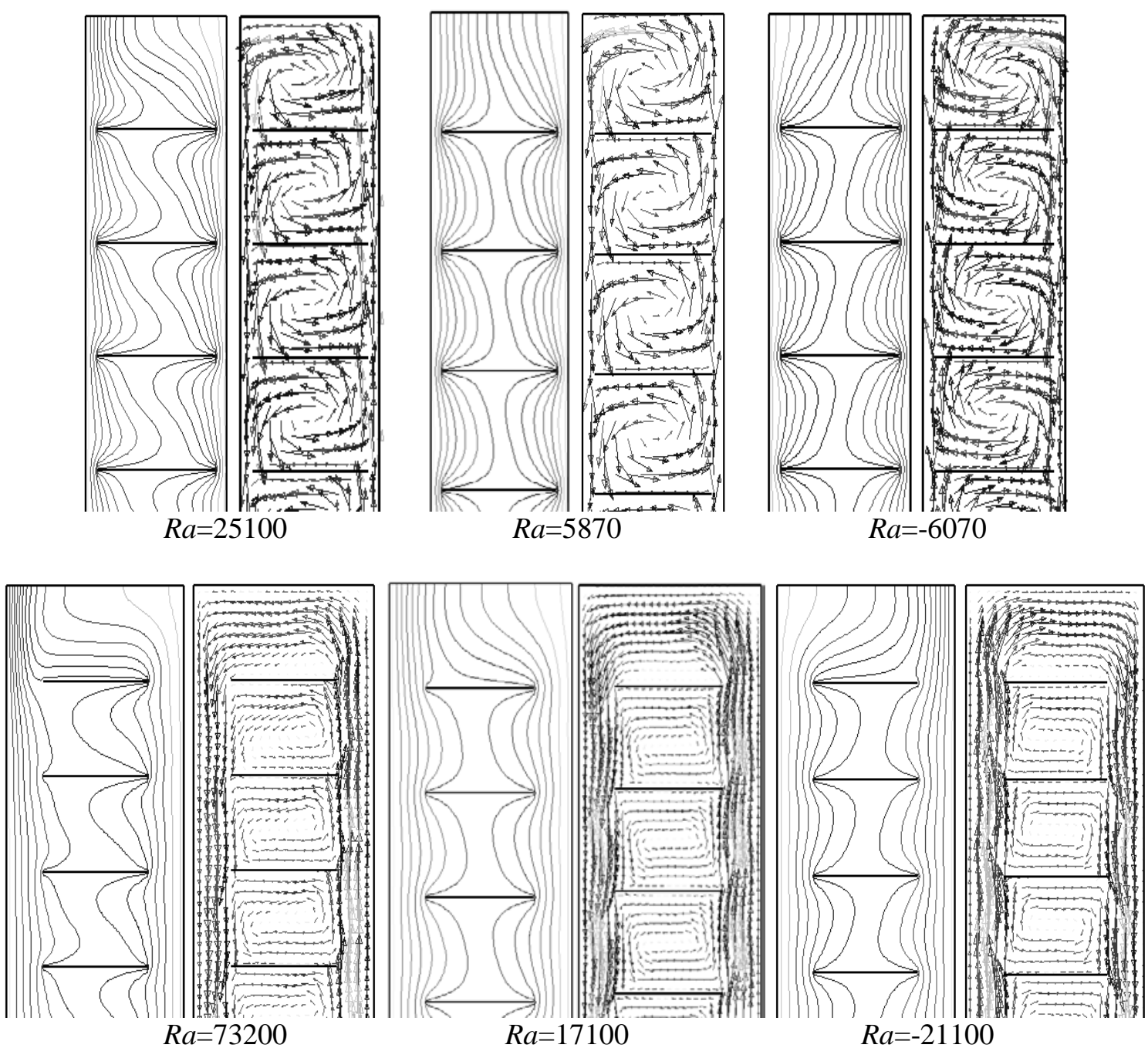

$T_{1}=-10^{0} \mathrm{C}, T_{2}=25^{\circ} \mathrm{C}$

$T_{1}=15^{\circ} \mathrm{C}, T_{2}=25^{0} \mathrm{C}$

$T_{1}=40^{0} \mathrm{C}, T_{2}=25^{0} \mathrm{C}$

Figure 5: Isothermal lines and velocity vectors for $W=17.8 \mathrm{~mm}$ (top), and 25.4mm (bottom). $\phi=0^{0}$ and $\Theta_{3}=0.5$. 


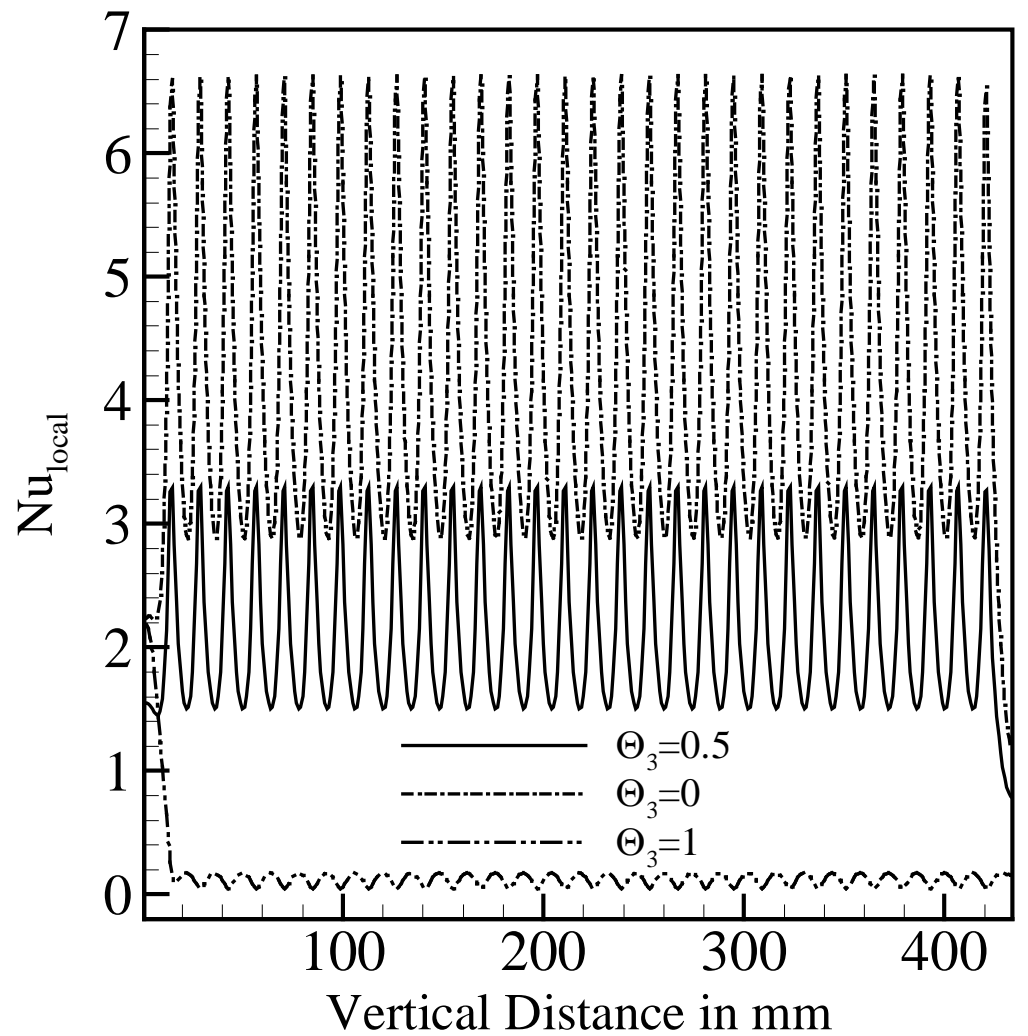

Figure 6: Variation of $N u_{\text {local }}$ along the right wall of the cavity for $W=17.8 \mathrm{~mm}, \phi=0^{0}, T_{1}=15^{0} \mathrm{C}$, and $T_{2}=25^{\circ} \mathrm{C}$. For left wall: $\theta_{3, \text { left }}=\left|\theta_{3}-1\right|$ and $N u_{\text {local,left }}=-N u_{\text {local }}$. 

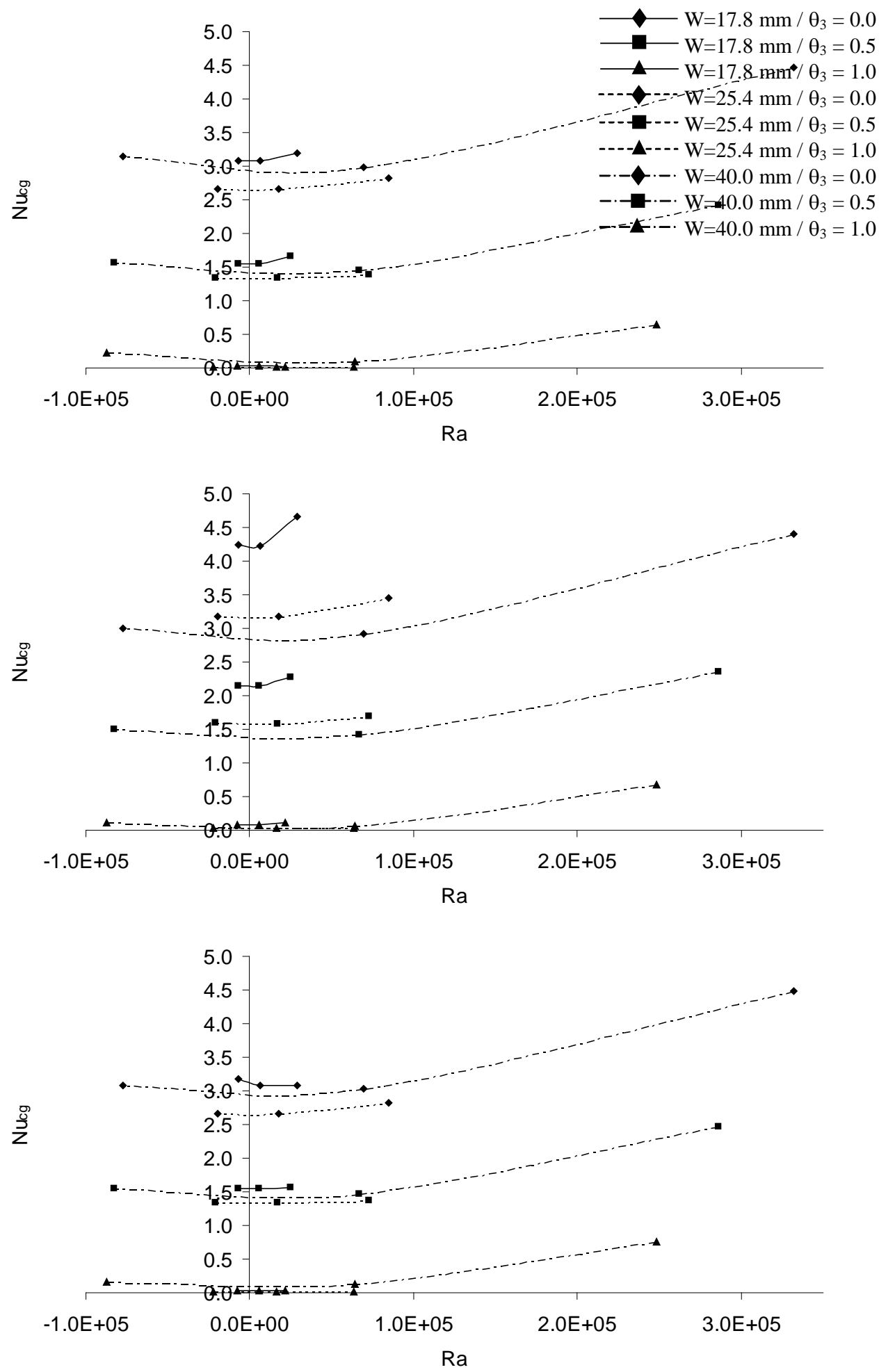

Figure 7: $N u_{c g}$ for $\phi=45^{\circ}$ (top), $\phi=0^{\circ}$ (mid), and $\phi=-45^{\circ}$ (bottom) on the right wall. For left wall: $\theta_{3, l e f t}=\left|\theta_{3}-1\right|$ and $N u_{c g, l e f t}=-N u_{c g}$. 